Canadian

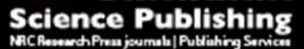

Canadian Journal of Civil Engineering Revue canadienne de génie civil

\title{
Real-time planning of a lifting scheme in mobile crane mounted controllers
}

\begin{tabular}{|r|l|}
\hline Journal: & Canadian Journal of Civil Engineering \\
\hline Manuscript ID & cjce-2015-0110.R2 \\
\hline Manuscript Type: & Article \\
\hline Date Submitted by the Author: & $29-$ Feb-2016 \\
\hline Complete List of Authors: & $\begin{array}{l}\text { Ren, Weijun; Chang'an University, School of Information Engineering } \\
\text { WU, Zifeng; University of Nebraska-Lincoln, Department of Civil } \\
\text { Engineering } \\
\text { Zhang, Lei; Chang'an University, School of Information Engineering }\end{array}$ \\
\hline Keyword: & $\begin{array}{l}\text { constr. management < Construction, construction (CA) < Computer } \\
\text { Applications, safety, path planning, lifting operation, mobile cranes, } \\
\text { construction machinery, construction management., english only < type of } \\
\text { paper to review }\end{array}$ \\
\hline \multicolumn{2}{|l}{} \\
\hline
\end{tabular}




\title{
Real-time planning of a lifting scheme in mobile crane mounted controllers
}

\author{
Weijun Ren \\ School of Information Engineering \\ Chang'an University \\ Middle Part of South 2nd Ring Road \\ Xi'an, Shaanxi, China, 710064 \\ Phone: +8613891993817 \\ E-mail: renweijunxa@126.com \\ (Corresponding author)
}

\author{
Zifeng Wu \\ Department of Civil Engineering \\ University of Nebraska-Lincoln \\ 2200 Vine St, 330G Whittier Research Center \\ Lincoln, Nebraska, U.S., 68508 \\ Phone: +1(402) 805-7074 \\ E-mail:wuzi620@gmail.com \\ Lei Zhang \\ School of Information Engineering \\ Chang'an University \\ Middle Part of South 2nd Ring Road \\ Xi'an, Shaanxi, China, 710064 \\ Phone: +8618391489919 \\ E-mail:593280281@qq.com
}

Submitted for presentation and publication in

Canadian Journal of Civil Engineering

Word Count:

Text: 7418

Table and Figures: 14 
Abstract: Ensuring the safety and efficiency of crane operation is challenging due to the complexity of lifting operation. The real-time lifting path planning system developed in this paper aims to provide an optimized, collision-free lifting path for mobile crane operators. The first contribution of the developed system is to take advantage of crane mounted sensors and components as the hardware to collect object information. No additional device needs to be purchased. Secondly, the data storage, path planning, optimizing, and visualizing functions are designed to minimize the required computer memory so that the system can be installed and applied on the crane mounted controller for real-time operation. No additional calculation capacity is required. This system has been tested in real construction sites and demonstrated its ability to generate lifting paths satisfying operators' expectation. The system, as an independent software package, can be installed on any mobile cranes mounted with the necessary hardware.

Key words: safety, path planning, lifting operation, mobile cranes, construction machinery, construction management. 


\section{Introduction}

Widely used cranes are also the source of world-wide safety concerns in manufacturing, construction, transportation, and other engineering industries. In China, for instance, there were 76 serious accidents involving crane machinery that occurred in 2012 and 61 serious accidents in 2013, which accounted for $33.3 \%$ and $26.87 \%$, respectively, of the total special equipment related accidents, and $44.2 \%$ and $29.07 \%$ of all worker deaths as a result of accidents related to special equipment (AQSIQ of P.R.C 2013; AQSIQ of P.R.C 2014). In Canada, there were 56 crane-related accidents recorded in the province of British Columbia in 2006 and 62 accidents in Quebec recorded from 1974 to 2002 (Zhang et al. 2012). Based on crane accident data, mobile cranes have been recognized as potentially more dangerous than other types of cranes due to their configuration and operation concepts (Shapira and Lyachin 2009; Peurifoy et al. 2010; King 2012). An earlier study by Compliance Safety and Health Officers (CSHOs) also indicated that over $88 \%$ of the 7,479 fatalities in the construction industry from 1991 to 2002 were mobile-crane related (Beavers et al. 2006). Taking a closer look at the causes of crane accidents reveals that human error plays an important role. In $42.7 \%$ of the incidents studied by King, crane operators were found to be at least partially at fault. These data suggest that more emphasis should be put on the development of intelligent assistance systems to enhance crane operation safety by reducing the likelihood of human errors. 
The planning of lifting paths is essential for crane operation in complex construction sites (Lin 2013). Collecting environment data of work sites is the first step for planning the lifting path. Extensive research efforts have been directed to equip cranes with advanced sensors to collect entity data from work sites in real time. Some tracking schemes were developed to track multiple workers on construction sites using video image processing technology and time-lapse photography (Yang et al. 2010; Jog et al. 2011; Kawai et al. 2008). Such image processing technology, however, requires significant computation power for real-time applications. In addition, the relative distances calculated through images tend to have high errors. Therefore, a variety of technologies such as Radar, Global Positioning System (GPS) (Wu et al. 2013), ultra-wideband sensor (Zhang et al. 2012), radio frequency (RF) remote sensor (Marayong et al. 2012), infrared detection (Ye 2010), and 3D laser scanners (Shih 2002) have been explored to identify the positions of objects in the same area as the cranes in operation to establish the $3 \mathrm{D}$ crane lifting environment.

The second core component in lifting motion planning is the optimization algorithms to search for the suitable lifting paths. In the construction domain, many algorithms have been studied to search for collision-free lifting paths based on the concepts of configuration space (C-space) and degrees of freedom (DOFs) (Pérez 1983; Choset et al. 2005). In this approach, a crane is studied as a robotic manipulator with multiple DOFs. C-space is the set of all possible configurations of a robot, and a configuration of a robot system is the complete specification of the position of every 
point in that system. Reddy et al. generated the C-space using an interference detection technique and searched for the optimal lifting path through two levels of a heuristic algorithm (Reddy et al. 2002). Garber and Lin proposed a constraint-based motion planning approach that transforms the motion planning problem into the simulation of a dynamical system in which the motion of each rigid robot is subject to geometric constraints (Garber and Lin 2002). Other searching algorithms developed to search for the optimal/feasible path without collision and overload from the origin position of a lifting object to its destination position include: the ant colony algorithm (Wang et al. 2011), the probabilistic roadmap method (Chang et al. 2012), the A star path-finding algorithm (Ali et al. 2005), the rapidly exploring random tree algorithm (Zhang and Hammad 2012), etc.

To combine the data collection, path planning, and lifting simulation functions, various integrated systems for lift planning have been developed. Taghaddos et al. employed a simulation-based approach to produce a heavy lifting planning system for mobile cranes (Taghaddos et al. 2010). A dual-crane scenario was used to demonstrate the sufficiency of the system to provide detailed simulation and visualization for crane manipulation and cooperation. Lei et al. presented a generic lift-path-checking system for megaprojects (Lei et al. 2013). Strukova and Istvanik developed a noncommercial software tool, the Mobile Crane Simulator, to visualize mobile crane operation in 3D (Strukova and Istvanik 2011). Hermann et al. presented an integrated system to select, position, and simulate mobile cranes for complex industrial projects (Hermann et al. 
2010). In addition, some computerized lift planning software (CLPS) (e.g., Lift Planner developed by Jim Meehan, Cranimation produced by craniMAX, the 3-D Lift Plan designed by A1 A Software, the KranXpert in Germany), are commonly used by average-sized crane rental companies for everyday jobs. These CLPS are able to produce drawings to plan and document critical lifts (Harrison 2010). However, they are generally used to manually plan the path for moving objects by considering obstacles in the 3D environment before performing lifting operations (AlBahnassi and Hammad 2012).

\section{Research Methodology}

This paper aims to develop a real-time, integrated, lifting path planning system that includes data collection, a path-searching algorithm, and simulation functions.

This integrated system requires efficient collection and storage of the position and shape of lifting objects and obstacles in a work zone to establish a 3D model of a work zone before lift planning. The literature review reveals that previous real-time data collection systems are mainly based on sensors. However, these sensors require extra costs, and some sensors cannot detect the shape of the obstacles effectively for the purpose of path planning. When the worksite is changed, these sensors need to be installed again. Therefore, the method is mostly applied in the pre-operation planning stage and is not a good fit for mobile cranes due to the changeable work environment. The integrated planning system developed in this paper is based on the boom head and 
existing sensors in the mobile crane and does not require additional devices. In addition, the date storage is also designed based on collectable position parameters from the crane sensors.

The searching algorithms developed based on C-space methodology generally require additional calculation capability and are difficult to implement in a crane mounted controller in real time. As the dimension of $\mathrm{C}$-space grows, these algorithms could become impractical if the $\mathrm{C}$-space is treated as a state-space model. The path-searching algorithm in this integrated system works efficiently in the crane mounted controller to prevent contact collisions and overloading in lifting operation at a jobsite. In addition, given the collision and overloading prevention objectives are satisfied, the searching algorithm is further optimized based on the operation efficiency by selecting the most achievable crane boom position.

Different from the off-line 3D simulation before lifting operation in previous research, the integrated planning system in this paper visualizes the generated lifting path in real time through a top-view and sectional view of the work site and crane operation. This enables the real-time simulation in a crane mounted controller to assist the crane operator in making safe decisions. 


\section{System architecture and function flowchart}

\subsection{Hardware architecture}

This real-time lifting planning system shares hardware with the existing crane lifting control system, and no extra device is required for its implementation. Its architecture is composed of four parts: the mounted controller with a monitor, the operation control handles, three control valves, and three sensors. These parts are the standard configuration of current mobile cranes. One example, the Qy80v all-terrain crane, is shown in Fig.1.

In Fig.1, the arrow (1) points to the boom head, the arrow (2) points to telescopic pump control valve, the arrow (3) points to boom length sensor, the arrow (4) points to crane boom, the arrow (5) points to luffing pump control valve, the arrow (6) points to elevation angle sensor, the arrow (7) points to operation cabin (including mounted controller, operation control handles), and the arrow (8) points to turntable (including rotary pump control valve, rotation angle sensor).

The communication among all the parts is through the crane's Controller Area Network (CAN) bus (Fig.2). The mounted controller in the operator cabin reads the current state of the operation control handles, which is driven by the crane operator, and then adjusts the intensity of the control current of the rotary pump control valve, the luffing pump control valve, and the telescopic pump control valve to regulate the speed 
and direction of crane boom movement. The real-time position parameters of the boom head (i.e., boom length, rotation angle, and elevation angle) measured by the boom length sensor, rotation angle sensor, and elevation angle sensor are the key inputs of the system. The mounted controller determines the current location of boom based on these measurements.

\subsection{Function flow chart}

The developed system software includes two sub-modules - the pre-process module and the lifting path planning module. The functions of the lifting scheme planning system are summarized within the flowchart shown in Fig.3.

The pre-process module is used to collect and save the position data of obstacles and lifting objects into the planning system. Obstacles are defined as objects that could potentially be involved in contact collisions with the crane during the lifting operation. The obstacle data are collected based on a pre-defined classification model using the boom head, and stored based on the position parameters of the boom head in a track-sector datasheet. The source and destination position of lifting objects are also collected by the crane boom head. In addition, the working range and loading chart in the crane lifting performance manual are also recorded in system. In lifting path planning module, all available lifting schemes are created based on the information from the crane lifting performance manual, the collected obstacle and lifting object data. A recommended lifting path is chosen according to a set of optimization rules from 
available schemes and simulated in real time.

\section{Pre-process module}

Considering the constraints and costs of additional devices for data collection, the boom head and existing sensors (i.e., boom length sensor, rotation angle sensor, and elevation angle sensor) on a mobile crane are used to collect obstacle information in this paper. The position and shape of obstacles are bound by collection points defined through a pre-defined classification model. For each collection point, the three position parameters of the boom head - the boom length, the rotation angle, and the elevation angle - are recorded by the crane's sensors. The position measurements are stored using a track-sector datasheet. To compute the relative position and the distance between obstacles and a crane, a cylinder coordinate system is developed to convert the position parameter measurements into the storage datasheet. Please refer to a previous study (Ren and $\mathrm{Wu} 2015$ ) for more details.

\subsection{Object classification model}

The boom head is used to collect obstacle data information, which means all of the objects to be collected need to be modeled by nodes. The collected points are used to represent and re-produce the obstacles in the system's memory. Therefore, the first step is to classify objects in a mobile crane's work so that a variety of object data can be 
collected efficiently. Table 1 lists the corresponding collection input points for different obstacle classes. To start the data collection for an obstacle, the operator selects the corresponding obstacle class on the mounted controller screen on the basis of the shape and size of the obstacle. The corresponding collection model with specified collection input points will be identified in the system interface. The operator moves the boom head to the target input point of the model, and presses the capture button on the system interface. The mounted controller automatically records the position parameters of the boom head (the boom length(r), the elevation angle $(\beta)$, and the rotation angle $(\varnothing)$ ) and sends them to the lifting planning system for conversion of the coordinates and data storage. After all of input points of the model are collected, the data collection process of the obstacle is finished.

\subsection{Cylinder coordinate system}

For each collected point, the coordinates are defined in a cylinder coordinate system. The cylinder coordinate system is the essential connection between the data collection and the data storage in the pre-process module. Although it is defined for the data collection by boom head in this paper, it will be compatible with other data collection methods, such as video data collection, data imported from Google Earth image, etc.

A cylinder coordinate system is proposed to represent the space around the crane efficiently. A crane's active work zone is bound by a cylinder of which the radius is the maximum length of the boom, and the height is the sum of the maximum length of the 
boom and the crane's body height. The cylinder coordinate system is derived based on the Cartesian coordinate system(XYZ), where origin $\mathrm{O}$ is the vertical projection in $\mathrm{X}_{-} \mathrm{Y}$ plane of the crane's rotation center $O_{1}$ located in the center of the crane's body, the $\mathrm{X}$ axis is the crane body axis, the positive $\mathrm{X}$ direction points toward the traveling cabin, and the $\mathrm{Z}$ axis, being perpendicular to the $\mathrm{X}$ axis, takes an upward direction from the rotation center. Following the right-hand rule, the $\mathrm{Y}$ axis is determined by the first two choices, sharing the same origin with $\mathrm{X}$ axis and $\mathrm{Y}$ axis (Fig.4).

As shown in Fig.4, for any point $\mathrm{P}$ in the work zone space, its cylinder coordinates are $(\varnothing, d, h)$, where $\varnothing$ is the counterclockwise azimuth angle of point D measured from the $\mathrm{X}$ axis, point $\mathrm{D}$ is orthogonal projection of point $\mathrm{P}$ on the $\mathrm{X} \_\mathrm{Y}$ plane, $\mathrm{d}$ is the distance from point $\mathrm{D}$ to origin $\mathrm{O}$, and $\mathrm{h}$ is the height from point $\mathrm{P}$ to point $\mathrm{D}$ on ground. Assuming that point $\mathrm{P}$ is one of the collection points defining an obstacle, the crane operator can move the crane's boom head to $\mathrm{P}$ and record location parameters of $\mathrm{P}$ : the boom length $\mathrm{r}$, the elevation angle $\beta$, and the rotation angle $\emptyset$. The cylinder coordinates of $P$ can be calculated from the measurements $(r, \beta, \emptyset)$ through equation (1). (1) $\varnothing=\varnothing, d=r \cdot \cos \beta-m, h=r \cdot \sin \beta+n$

Where the distance $\mathrm{m}$ is from $B_{0}$ to the crane's rotation center $O_{1}, \mathrm{~B}_{0}$ is the hinge point between the boom and the crane chassis $\left(B_{0} B_{1} B_{2}\right)$, and the height $\mathrm{n}$ is the crane's body height from 0 to $O_{1}$. 


\subsection{Obstacle data storage}

As an analogy to the track sector of the gramophone record, a track-sector structure is proposed for the obstacle data storage. The bottom disk of the cylinder of a crane's work zone is divided into tracks - concentric circular strips with a width of $0.1 \mathrm{~m}$. Each track is further cut into 3600 sectors, each subtending to a central angle of $0.1^{\circ}$. Each track-sector cell records the bottom and upper bounds $\left[\mathrm{B}_{\left(\emptyset_{\mathrm{i}}, \mathrm{d}_{\mathrm{i}}\right)}, \mathrm{U}_{\left(\emptyset_{\mathrm{i}}, \mathrm{d}_{\mathrm{i}}\right)}\right]$ of the safety range for the crane movements in terms of height. For example, a track-sector datasheet, as shown in Table 2, indicates that for the track-sectors at $0.2^{\circ}-0.3^{\circ}$ within $0.2 \mathrm{~m}$ from the rotation center $\mathrm{O}$, a crane is safe to move from the ground (i.e., $0.0 \mathrm{~m}$ ) to a height of $80 \mathrm{~m}$. In this case, a hanging obstacle exists above $80 \mathrm{~m}$, which could be a ceiling. Moreover, if the crane continues moving to the tracks from $0.2 \mathrm{~m}$ to $0.4 \mathrm{~m}$ without changing the rotation angle $\emptyset$, there will be additional at-ground obstacles under the height of $6.8 \mathrm{~m}$. The maximum boom length is assumed to be $100.0 \mathrm{~m}$ in this paper.

\section{Lifting path planning module}

The location and shape data of all immobile objects in the work area have been collected by a boom head and stored in a track-sector datasheet. If the location and shape of obstacles in the work zone change, the datasheet can be updated in real time by re-collecting information using the boom head. The lifting path planning module in the integrated system will optimize and simulate the lifting path based on the source and 
destination position of lifting objects that are also collected by using the crane boom head. In addition to the work zone environment data, the optimized lifting path is created based on the working range and loading chart in the crane lifting performance manual.

\subsection{Information collection of lifting object}

The crane driver moves the crane boom head to directly over the source position of the lifting object and collects the data $P_{s}\left(r_{s}, \beta_{s}, \emptyset_{s}\right)$. The cylinder coordinates $P_{s}\left(\emptyset_{s}, d_{s}, h_{s}\right)$ can be computed using the coordinate system conversion equation (1). Similarly, the position data of the destination point $P_{d}\left(\emptyset_{d}, d_{d}, h_{d}\right)$ can be collected by moving the boom head to the destination of the lifting object. The weight $W_{l}$ and height $H_{l}$ of the lifting object are estimated. The crane lifting performance manual is stored in the crane mounted controller. This manual includes the working range and the information of the load charts to avoid overloading and guarantee safe lifting operation. The working range shows the minimum and maximum boom angles according to the length of the boom and the size of the counterweight. The load charts give the lifting capacity based on the boom length, the boom angle to the ground, and the size of the counterweight.

\subsection{Real-time planning of lifting scheme}

The proposed real-time optimization algorithm to generate a lifting path considering engineering constraints is demonstrated in a flowchart in Fig.5. For better readability, not 
all of the details are included in the flowchart. Each step in the flowchart is explained with more details in the following sub-sections.

\subsubsection{Initializing lifting scheme table}

The lifting scheme table shows the lifting path step by step. Each step records the boom elevation angles corresponding to a certain boom rotation angle given a fixed boom length. This table is initialized as blank at the beginning of the optimization process.

\subsubsection{Choosing the boom rotation direction}

The boom rotation direction is determined based on the objective of minimizing the boom rotation angle in the lifting process from the source position $P_{s}\left(\emptyset_{s}, d_{s}, h_{s}\right)$ to the destination position $P_{d}\left(\emptyset_{d}, d_{d}, h_{d}\right)$ of the lifting object. If $\emptyset_{\mathrm{d}} \geq \emptyset_{\mathrm{s}}$ and $\emptyset_{\mathrm{d}}-\emptyset_{\mathrm{s}} \leq$ $180^{\circ}$, the rotation direction is counterclockwise, and the rotation angle $\emptyset_{\mathrm{n}}$ is $\emptyset_{\mathrm{d}}-\emptyset_{\mathrm{s}}+$ $1^{\circ}$. If $\emptyset_{\mathrm{d}} \geq \emptyset_{\mathrm{s}}$ and $\emptyset_{\mathrm{d}}-\emptyset_{\mathrm{s}}>180^{\circ}$, the rotation direction is clockwise, and the rotation angle $\emptyset_{\mathrm{n}}$ is $360^{\circ}-\left(\emptyset_{\mathrm{d}}-\emptyset_{\mathrm{s}}\right)+1^{\circ}$. If $\emptyset_{\mathrm{d}}<\emptyset_{\mathrm{s}}$ and $\emptyset_{\mathrm{s}}-\emptyset_{\mathrm{d}}<180^{\circ}$, the rotation direction is clockwise, and the rotation angle $\emptyset_{\mathrm{n}}$ is $\emptyset_{\mathrm{s}}-\emptyset_{\mathrm{d}}+1^{o}$. Otherwise, the rotation direction is counterclockwise, and the rotation angle $\emptyset_{\mathrm{n}}$ is $360^{\circ}-\left(\varnothing_{\mathrm{s}}-\emptyset_{\mathrm{d}}\right)+$ $1^{o}$. If the rotation direction is clockwise, the rotation step is defined as $\emptyset_{\text {step }}=-0.5^{o}$, otherwise $\emptyset_{\text {step }}=0.5^{\circ}$.

\subsubsection{Calculating the boom length range}

1) The maximal amplitude position $d_{m}$ is determined according to the amplitude value $d_{s}$ in source position $P_{s}\left(\emptyset_{s}, d_{s}, h_{s}\right)$ and amplitude value $d_{d}$ in destination position $P_{d}\left(\emptyset_{d}, d_{d}, h_{d}\right)$ of the lifting object. If $d_{s}>d_{d}$, then $d_{m}=d_{s}$, otherwise 
$d_{m}=d_{d}$

2) The collision-free range for the boom length within, which the boom can stretch without collision with on-site obstacles, is determined based on the sector column in the track-sector sheet corresponding to the maximal amplitude $d_{m}$. Fig.6 illustrates an example to calculate the boom length range. Assuming there are three obstacles $\mathrm{O}_{1}, \mathrm{O}_{2}$, and $O_{3}$ on the ground and an obstacle $O_{4}$ on the ceiling in this sector (Fig.6), the elevation angle range within which the boom can rise without collision with these obstacles in the $d_{m}$ position is from $\beta_{\min }$ to $\beta_{\max }$. The boom length range $\left[L_{\min }, L_{\max }\right]$ can be calculated based on the elevation angle range $\left[\beta_{\min }, \beta_{\max }\right]$ using equation (2), where the angle $1^{o}$ is the safety buffer.

(2) $L_{\min }=d_{m} / \cos \left(\beta_{\min }+1^{o}\right), L_{\max }=d_{m} / \cos \left(\beta_{\max }-1^{o}\right)$

3) The working range and loading chart of the crane is queried using the value of the maximal amplitude position $d_{m}$ to decide the boom length range $\left[L_{\text {min }}^{\prime}, L_{\text {max }}^{\prime}\right]$, where the lifting capacity is equal to or greater than the lifting object estimated weight $W_{l}$.

4) The intersection set of $\left[L_{\min }, L_{\max }\right]$ and $\left[L_{\min }^{\prime}, L_{\max }^{\prime}\right]$ is calculated to finalize the boom length range $\left[L_{r m i n}, L_{r m a x}\right]$. If the crane uses a plug-pin luffing boom, the length range is not continuous. If the intersection set is null, there is no available boom length and no lifting path can be generated, and the path-searching process stops.

\subsubsection{Selecting boom length and elevation angle}

The first step to create a lifting path is to start from the source position point. This section will present the selection of the boom length and the elevation angle for the 
source position point. At all the other points during the lifting position, the selection of the boom length and the elevation angle for the next step can be implemented through similar methods. The boom elevation angle range for the source position $P_{s}\left(\emptyset_{s}, d_{s}, h_{s}\right)$, denoted as $\left[\beta_{\text {smin }}, \beta_{\text {smax }}\right]$, can be obtained from the pre-collected environment data in the track-sector sheet corresponding to the line of $\emptyset_{s}$. Fig.7 is used to illustrate the selection of the boom length and the elevation angle.

The minimum length from $\left[L_{r m i n}, L_{r \max }\right]$ is selected as an initial boom length $L_{i}$, and the initial elevation angle $\beta_{i}$ is calculated using equation $\cos \beta_{i}=d_{s} / L_{i}$. The boom length usually remains fixed during the whole lifting process. If $\beta_{i}$ is within the limits of $\left[\beta_{\text {smin }}, \beta_{\text {smax }}\right], L_{i}$ and $\beta_{i}$ are chosen as the pre-selected lifting boom length $L_{r}$ and elevation angle $\beta_{r}$ (Fig.7-(a)). If not, the range of $\left[L_{r m i n}, L_{r m a x}\right]$ should be returned to in order to choose a new minimum length $L_{n}$. Thus, a new elevation angle $\beta_{n}$ is calculated based on the $L_{n}$. This process is repeated until the resulting $\beta_{n}$ is within the range of $\left[\beta_{\text {smin }}, \beta_{\text {smax }}\right]$, or there is no boom length to choose in the range of $\left[L_{r \min }, L_{r \max }\right]$. If $\beta_{n}$ and $L_{n}$ are both available, they are the selected lifting boom length $L_{r}$ and elevation angle $\beta_{r}$ (Fig.7-(b)). If there is no available $\beta_{n}$, no lifting path can be generated and the path-searching process stops.

\subsubsection{Calculating the elevation angle for each rotation angle}

Assume that the boom rotation angle of previous position is $\emptyset_{p}$ and the pre-selected elevation angle is $\beta_{p}$. According to the rotation direction of the boom, the current rotation angle $\emptyset_{c}$ is $\emptyset_{p}+\emptyset_{\text {step }}$, where $\emptyset_{\text {step }}$ is a pre-defined rotation angle increment for the 
next step. The boom length $L_{r}$ remains fixed.

First, the pre-selected elevation angle $\beta_{p}$ is double checked based on the environment data for the line of rotation angle $\emptyset_{c}$ in the track-sector sheet. The current amplitude value $d_{c}$ is $L_{r} \cdot \cos \beta_{p}$. The range of the elevation angle is $\left[\beta_{c m i n}, \beta_{c m a x}\right]$, which is determined by environment data in the cell corresponding to the line of $\emptyset_{c}$ and the column of $d_{c}$. If $\beta_{p}$ is within the range of $\left[\beta_{c m i n}, \beta_{c m a x}\right], \beta_{p}$ is selected as the current lifting elevation angle $\beta_{c}$ for the current rotation angle $\emptyset_{\mathrm{c}}$ (Fig.8-(a)).

If $\beta_{p}$ is not within the range of $\left[\beta_{c m i n}, \beta_{c m a x}\right]$, the crane boom is raised by $0.5^{o}$ to the elevation angle $\beta_{a s c}$, and $\beta_{a s c}=\beta_{p}+0.5^{\circ}$. The new amplitude value $d_{a s c}$ is calculated with elevation angle $\beta_{a s c}$ and boom length $L_{r}$, and the elevation angle range $\left[\beta_{\text {amin }}, \beta_{\text {amax }}\right]$ is obtained from the track-sector cell at the line of $\emptyset_{c}$ and the column at $d_{a s c}$. If $\beta_{a s c}$ is within the range of $\left[\beta_{a m i n}, \beta_{a m a x}\right], \beta_{a s c}$ is chosen as the lifting elevation angle $\beta_{c}$ in the rotation angle $\emptyset_{c}$ position (Fig.8-(b)). If not, the crane boom raises another $0.5^{\circ}$ to the elevation angle $\beta_{a s c}^{\prime}$, and $\beta_{a s c}^{\prime}=\beta_{a s c}+0.5^{\circ}$. The process is repeated until a $\beta_{a s c}^{\prime}$ is found to be within the range of $\left[\beta_{a \min }, \beta_{a \max }\right]$, or the condition $\beta_{a s c}^{\prime} \geq 85^{\circ}$ is satisfied. The maximal elevation angle that boom can rise to is $85^{\circ}$. Therefore, if the condition $\beta_{a s c}^{\prime} \geq 85^{\circ}$ is satisfied, no elevation angle $\beta_{c}$ can be found for the current rotation angle $\emptyset_{c}$. In this case, the crane boom descends $0.5^{\circ}$ from elevation angle $\beta_{p}$ to elevation angle $\beta_{d e s}$, and $\beta_{d e s}=\beta_{p}-0.5^{\circ}$. The new amplitude value $d_{d e s}$ and the elevation angle range $\left[\beta_{d m i n}, \beta_{d m a x}\right]$ can be obtained from the track-sector sheet in the same way as for $\beta_{a s c}$. If $\beta_{\text {des }}$ is within the 
range $\left[\beta_{d \min }, \beta_{d \max }\right]$, and the lifting object weight $W_{l}$ is lower than the lifting capacity recorded in the load charts with the amplitude value $d_{d e s}$ and boom length $L_{r}, \beta_{d e s}$ is chosen as the lifting elevation angle $\beta_{c}$ (Fig.8-(c)). If not, the crane boom further descends $0.5^{\circ}$ to reach the elevation angle $\beta_{d e s}^{\prime}$, and $\beta_{d e s}^{\prime}=\beta_{d e s}-0.5^{\circ}$. This process is repeated until $\beta_{d e s}^{\prime}$ is found to be within the range of $\left[\beta_{d m i n}, \beta_{d m a x}\right]$ or $\beta_{d e s}^{\prime} \leq$ $5^{\circ}$. The minimal elevation angle which boom can descend to is $5^{\circ}$.

If $\beta_{\text {des }}^{\prime} \leq 5^{o}$ is satisfied, an acceptable elevation angle $\beta_{c}$ cannot be found by rising and descending the boom with a length of $L_{r}$ and a rotation angle of $\emptyset_{c}$. A new boom length $L_{r}^{\prime}$ needs to be chosen from $\left[L_{r m i n}, L_{r m a x}\right]$ and judged for whether or not an available elevation angle can be found at each rotation angle from the source position $P_{s}\left(\emptyset_{s}, d_{s}, h_{s}\right)$ to the destination position $P_{d}\left(\emptyset_{d}, d_{d}, h_{d}\right)$. If all of the selectable boom lengths do not generate an acceptable elevation angle $\beta_{c}$, the opposite direction of last rotation direction and the boom length $L_{r}$ is chosen again from $\left[L_{r m i n}, L_{r m a x}\right]$ and judged for whether or not an acceptable elevation angle exists at each rotation angle from the source position $P_{s}\left(\emptyset_{s}, d_{s}, h_{s}\right)$ to the destination position $P_{d}\left(\emptyset_{d}, d_{d}, h_{d}\right)$ in the other boom rotation direction. If all of the selectable boom lengths still do not lead to a workable result, no lifting path can be created and the path-searching process stops.

\subsection{Optimizing lifting scheme}

If lifting paths can be created for multiple boom length choices, the number of times to change elevation angles in all the lifting paths from the source position to the 
destination position are calculated and compared. The optimal path is the one which makes minimal changes. If there is more than one path that has the same changes in elevation angles, the one with the shortest boom length is chosen. If the boom length is the same for multiple generated paths, the optimal scheme is the one that has minimal changes in the rotation angle of boom. After the optimal path is selected, according to the boom length value of this scheme, the cable combination and multiple ratios, hook type and weight, and other parameters will be selected.

\subsection{Real-time online simulation of lifting scheme}

The real-time work zone is simulated for and visualized to the crane operator through a combination of a top-view and a sectional view on the monitor of the crane mounted controller. The boom moving process from the source position to the destination position based on the selected lifting path is visually accessible to the operator to assist this operation and real-time decision making.

\section{System implementation and evaluation}

The developed lifting planning system is an independent module that does not impair or slow down the existing intelligent control system of mobile cranes, and is easy to install on a crane-mounted controller. The system is compatible with existing crane-mounted control systems, and can function efficiently as long as real-time position 
parameters of the boom head are readable from the crane CAN bus. These parameters are measured by the boom length sensor, rotation angle sensor, and elevation angle sensor and sent to the existing control system of cranes through the crane CAN bus.

The system was installed tentatively on a QAY all-terrain crane and a RT wheel crane that were produced by the XCMG Company in China and equipped with the eVision2-10.4T mounted controller, PAT-LWG208 elevation angle sensor, PAT-LWG152 boom length sensor, and RON786 rotation angle sensor. The system was also tested on a Qy80V truck crane produced by the Zoomlion Company in China that was equipped with the TPC-1051WP mounted controller, HA-JD-01R elevation angle sensor, HA-CD-02R boom length sensor, and ETF100 rotation angle sensor. The three models selected to validate the performance of the lifting planning system are: the QAY260 all-terrain crane, Qy80VF532 truck crane, and RT80 wheel crane. The system and data logger were installed on six cranes - two for each crane model. Six operators were randomly selected from the XCMG company testing center. Six different lifting jobsites were selected as test beds. One of the test beds is shown in Fig.9. The six operators applied the lifting planning system in their routine lifting tasks for one week, generating 216 test operations.

When a lifting task was needed, the available position in the jobsite for crane parking was selected first according to the pick-up location, the location of lifting objects, and environment of the jobsite. After a mobile crane entered the jobsite, the shape and location data of all the obstacles and lifting objects in the work zone, and the distances between the crane and obstacles, were measured and recorded manually. Then, the 
operator started the lifting planning system to collect obstacle data through the user interface shown in Fig.10. The gray bar on the top shows the current position parameters of the boom head. The operator needs to click on the matching classification of the obstacle from the left-top panel to call up the corresponding data collection panel on the right. Each obstacle class relates to its corresponding data collection module, which is shown in the right panel. In the example shown in Fig.10, the ground cylinder class was selected. Fig.9 gives some other examples of obstacle classification including: 1) three buildings and building materials that are classified as cube objects, 2) an electric cabinet is classified as a cylinder object, 3) and hanging power lines are classified as hanging objects. Then, the operator needs to move the boom head to the specific points listed in the right panel to collect required inputs. The right panel currently shows the three points to be collected for the cylinder object. The operator can click on the "Recollect" button to recollect the data of the point. The "Finish collection" button pops up after all the required points are collected. The lower-left corner is a top-view of the work zone around the crane displaying the location and shape of the obstacles already collected and stored. Based on all the collected obstacle information, this system can automatically perform the required calculations to fill the track-sector datasheet. In addition, the "Mend\&Del" button enables the operator to change and delete the collected information of the obstacles if necessary. The "Con-collect" button enables the operator to continue collecting the inputs required for the next obstacle. The "Back" button enables the operator to exit the data collection interface and go back to the main interface of the 
system.

The user interface for collecting the information for lifting objects is shown in Fig.11. The upper-left panel displays the information collected for a lifting object. The operator moves the boom head to the right over the source position of the lifting object and clicks on the "collect" button to record the position parameters for the source position, and moves the boom head to the right over the destination position of the lifting object to collect destination information. The weight and height of the lifting object are input in the system by the operator through the center panel. The upper-right corner is a top-view of the work zone around the crane displaying the location and shape of the obstacles as well as the source and destination position of the lifting object.

After the obstacle and lifting object information is collected, the lifting path is automatically created and displayed in the lower panel of the simulation interface of the planning system. Fig.12 shows one example of the interface screenshot. In this example, the boom length is $23.0 \mathrm{~m}$, and the boom rotation direction is clockwise; the current page shows 24 steps for the lifting path. The current elevation angle is selected as $36.4^{\circ}$, and the operator needs to rotate the boom from the rotation angle $46^{\circ}$ to $38^{\circ}$ to finish step 1 through 9. At step 10, the elevation angle is changed to $39.0^{\circ}$, and the rotation angle is set as $37.0^{\circ}$. In steps 10 through 24 , the elevation angle remains the same, and the operator needs to rotate the boom from the rotation angle $37.0^{\circ}$ to $23.0^{\circ}$. The rest of the path can be viewed by pressing "Down-page" button. In the meantime, the planned path is simulated in real time through a top-view and a sectional view as shown in the 
upper-right and upper-left panels of Fig.12, respectively. The top-view is created by viewing the work zone from top to bottom to show the plane picture of all the obstacles in the jobsite, and the sectional view provides a vertical view with a cutting line at the center of the crane boom, which displays the height of the obstacle compared to the boom head.

The performance of the obstacle data collection module was validated by comparing two datasets of the obstacles that were collected by the system and by hand. The evaluation based on the 216 test operations indicated that the system can efficiently collect $96.8 \%$ of the obstacles in the tested jobsites; the mean of the relative errors of detecting distances from obstacles to cranes was $3.27 \%$, and the standard deviation of the relative error was $1.47 \%$. The mean and standard deviation of the relative errors of the volume calculation of obstacles were $5.63 \%$ and $3.42 \%$. The 216 optimal lifting paths were successfully created and simulated by the system for the 216 test operations. The results of the simulation and operation showed that no collisions or overloading occurred while using these optimized lifting paths. Additionally, ten experienced crane operators were invited to grade these 216 lifting schemes, and the mean of the 216 scores was 83.6 .

Moreover, two-hundred questionnaires were distributed to the customers who used this lifting planning system to evaluate the system performance regarding their first three-month experience. The results of the 162 returned questionnaires showed that $74.3 \%$ of users were satisfied with the performance of the system, $17.4 \%$ of users gave the system an average rating, and $8.3 \%$ of users gave it a negative evaluation. 


\section{Conclusion}

A real-time lifting path planning system is developed in this paper to provide an optimization lifting scheme for crane operators before lifting operations. First, the shape and the location data of obstacles and lifting objects are collected by the boom head through a self-exploration method based on an obstacle classification model. The collected location data $P(r, \beta, \emptyset)$ is converted to the proposed cylinder coordinates $P(\emptyset, d, h)$ for storage purposes. The storage datasheet is in the format of a track-sector structure where the safety ranges for each track-sector $(\varnothing, d)$ are stored as an interval with upper and bottom bounds. Based on the track-sector datasheet, the $3 \mathrm{D}$ model of work zone is built with a top-view and a sectional view in the crane mounted controller. Second, the source and destination position of lifting objects are collected by the crane boom head, and the weight and height of the lifting object are estimated and inputted into the system. The boom rotation direction is chosen so the change in rotation angles of the boom in the lifting process from the source position to the destination position of the lifting object is minimized. Lifting schemes composed of: 1) the boom length and elevation angles at each rotation angle of the boom, 2) the cable combination and multiple ratios, and 3) the hook type and weight are created in real-time based on the track-sector datasheet and crane lifting performance manual. These lifting schemes are optimized and simulated on the crane mounted controller.

To conclude, the real-time integrated system developed in this paper can generate an 
optimized lifting path to avoid collision and overloading, and visualize the lifting operation in a cost-effective way. The advantages of this system mainly include three aspects:

(1) The location and shape information of obstacles are collected using the boom head, so the system do not require any extra cost to equip external sensors. If the obstacle location and/or shape changed during the operation, the information can be re-collected in real-time. The capability of collecting data using an existing crane controller and sensors does not require additional computation capacity and memory for data storage, which enables the real-time application of the system in mobile crane.

(2) The optimization algorithm is based on the working range, load chart and the three engineering constraints on boom length, elevation angle, and rotation angle. This algorithm is easy to implement and can generate results efficiently for real-time application. Previous research in the lifting path optimization generally treated a crane as a multi-degree-of-freedom robotic manipulator and adopts searching algorithms to find feasible paths in the C-space while preventing collisions and overloading during lifting operations. These searching algorithms require additional calculation capability, which makes them difficult to implement in crane mounted controllers in real-time.

(3) The simulation is realized through the combination of a top view and a sectional view of the work site. This method saves the capacity and memory necessary for real-time simulation and enables real-time visualized assistance to crane operators on the crane-mounted controller. 
The limitations of this research, however, include (1) the process of collecting information of obstacles in a work zone needs an operator's manipulation, and (2) the data collection method is designed for still obstacles in a work zone. Therefore future research is to find a way to automatically collect information of work zone without the need for operator intervention, such as video data collection, data imported from Google Earth image and so on.

\section{Acknowledgements}

The paper is supported by the Postdoctoral Natural Science Foundation of China (Grant No. 2013M532003), the Fundamental Research Funds for the Central Universities of China (Grant No. CHD2011JC179), and the Jiangsu Doctor Accumulation Plan Funds Project (Grant No. 2012097).

\section{References}

Albanese, H., and Hammad, A. 2012. Near real-time motion planning and simulation of cranes in construction: framework and system architecture. J. Comput. Civ. Eng. 26(1):54-63.

doi: $10.1061 /($ ASCE) CP.1943-5487.0000123

Ali, A.D., Babu, N.R., and Varghese, K. 2005. Collision free path planning of cooperative crane manipulators using genetic algorithm. J. Comput. Civ. Eng. 19(2): 182-193.

doi: 10.1061/(ASCE)0887-3801(2005)19:2(182) . 
Beavers, J.E., Moore, J.R., Rinehart, R., and Schriver, W.R. 2006. Crane-related fatalities in construction industry. J. Constr. Eng. Manage. 132(9): 901-910. doi: 10.1061/(ASCE)0733-9364(2006)132:9(901)

Chang, Y.C., Hung, W.H., and Kang, S.C. 2012. A fast path planning method for single and dual crane erections. Autom. Constr. 22(2):468-480. doi:10.1016/j.autcon.2011.11.006.

Choset, H.M., Lynch, K.M., and Hutchinson, S. 2005. Principles of robot motion-theory, algorithms, and implementations. MIT Press, Boston, MA. ISBN-13: 978-0262033275.

General Administration of Quality Supervision, Inspection and Quarantine of P.R.C. 2014. The safety using briefing on special equipment of China in 2013 [online]. Available from http://www.aqsiq.gov.cn/xxgk_13386/tzdt/zztz/201405/t20140514_412493.htm [accessed 10 March 2015].

General Administration of Quality Supervision, Inspection and Quarantine of P.R.C. 2013. The safety using briefing on special equipment of China in 2012[online]. Available from http://www.aqsiq.gov.cn/xxgk_13386/tjxx/tjfx/201306/t20130609_361071.htm[accessed 10 March 2015]

Garber, M., and Lin, M.C. 2002. Constraint-based motion planning for virtual prototyping. Proceedings of ACM Symposium on Solid Modeling and Applications, Saarbrucken, Germany, 17 -21 June, 2002. pp. 257-264. doi: 10.1145/566282.566320

Harrison, M. 2010. A review of lift planning software. Crane Hot Line, 2010(1):12-14. Available from http://www.harrisoncrane.com/pdfs/articles/clps_article.pdf [accessed 20 November 2014]

Hermann, U.R., Hendi, A., Olearczyk, J., and Al-Hussein, M. 2010. An integrated system to select, 
position, and simulate mobile cranes for complex industrial projects. Construction Research

Congress 2010, Banff, Alberta, Canada, 8-10 May 2010. pp. 267-276. doi: 10.1061/41109(373)27.

Jog, G.M., Brilakis, I.K., and Angelides, D.C. 2011. Testing in harsh conditions: tracking resources on construction sites with machine vision. Autom. Constr. 20(4):328-337.

doi:10.1016/j.autcon.2010.11.003.

Kawai, H., Choi, Y., Kim, Y. B., and Kubota, Y. 2008. Position measurement of container crane spreader using an image sensor system for anti-sway controllers. International Conf. on Control, Automation and Systems, IEEE, Seoul, 14-17 Oct 2008. pp. 683-686. doi:

10.1109/ICCAS.2008.4694588

King, R.A. 2012. Analysis of crane and lifting accident in North America from 2004 to 2010. M.Sc. thesis, Department of Civil and Environment Engineering, Massachusetts Institute of Technology, Cambridge, MA. Available from http://hdl.handle.net/1721.1/73792 [accessed 20 November 2014].

Lei, Z., Taghaddos, H., Olearczyk, J., Al-Hussein, M., and Hermann, U. 2013. Automated method for checking crane paths for heavy lifts in industrial projects. J. Constr. Eng. Manage. 139(10):

135-140. doi: 10.1061/(ASCE) CO.1943-7862.0000740.

Lin. Y.S. 2013. Research on computer aided crane selection and lifting planning. Ph.D. thesis, Dalian University of Technology, Dalian, China.

Marayong, P., and Yeh, H. 2012. Computer-aided container handling assistance for ergonomic crane operation. METRANS Project, California State Univ., Long Beach, CA. Available from https://rid.trb.org/view.aspx?id=1225231 [accessed 20 November 2014] 
Neitzel, R.L., Seixas, N.S., and Ren, K.K. 2001. A review of crane safety in the construction industry.

J. Appl. Occup. Environ. Hyg. 16(12): 1106-1117. doi: 10.1080/10473220127411

Peraza, D.B., and Travis, J.A. 2009. Crane safety—an industry in flux. Fifth Forensic Engineering

Congress, Washington, D.C., United States, 11-14 November 2009. pp. 556-566, doi:

$10.1061 / 41082(362) 57$.

Perez, L. 1983. Spatial planning: A configuration space approach. IEEE Trans. Comput.

C-32(2):108-120. doi: 10.1109/TC.1983.1676196.

Peurifoy, R.L., Schexnayder, C.J., and Shapira, A. 2010. Construction planning, equipment, and methods, 8th Ed., McGraw-Hill, New York. ISBN-13: 978-0071289511.

Reddy, H.R., and Varghese, K. 2002. Automated path planning for mobile crane lifts. Comput.-Aided

Civ. Infrastruct. Eng. 17(6): 439-448. doi: 10.1111/0885-9507.00005.

Ren, W. J., and Wu, Z. F. 2015. Real-time anti-collision system for mobile cranes during lift

operations. J. Comput. Civ. Eng. 29(6): 04014100. doi: 10.1061/(ASCE)CP.1943-5487.0000438

Shapira, A., and Lyachin, B. 2009. Identification and analysis of factors affecting safety on construction sites with tower cranes. J. Constr. Eng. Manage.135 (1):24-33. doi:

10.1061/(ASCE)0733-9364(2009)135:1(24).

Shih, N. J. 2002. An application of a 3D scanner in the representation of building construction site.

Proceedings of the 19th ISARC, Gaithersburg, M.D, 23-25 September 2002. pp.337-342.

Available from http://www.iaarc.org/publications/fulltext/ISARC-2002-090.pdf [accessed 12

November 2014].

Strukova, Z., and Istvanik, M. 2011. Tools for mobile crane selecting and locating. Int. Rev. Appl. Sci. 
Eng. 2(1): 69-74. doi: 10.1556/IRASE.2.2011.1.11.

Taghaddos, H., AbouRizk, S., Mohamed, Y., and Hermann, U. 2010. Simulation-based multiple heavy lift planning in industrial construction. Construction Research Congress, Banff, Alberta, Canada, 8-10 May 2010. pp.349-358. doi: 10.1061/41109(373)35.

Wang, X., Zhang, Y., Wu, Y.D., and Gao, S.D. 2011. Collision-free path planning for mobile cranes based on ant colony algorithm. Key Eng. Mater. 467-469: 1108-1115. doi: 10.4028/KEM.467-469.1108.

Wu, H., Tao, J., Li, X., and Chi, X. 2013. A location based service approach for collision warning systems in concrete dam construction. Saf. Sci. 51(1):338-346. doi: 10.1016/j.ssci.2012.08.006

Yang, J., Arif, O., Vela, P. A., Teizer, J., and Shi, Z. 2010. Tracking multiple workers on construction sites using video cameras. Adv. Eng. Inf. 24(4): 428-434. doi: 10.1016/j.aei.2010.06.008.

Ye, X. 2010. Design of embedded infrared detection-based anti-collision system for bridge cranes. Hoisting and Conveying Machinery, 2: 23-25. Available from http://en.cnki.com.cn/Article_en/CJFDTOTAL-QZJJ201002009.htm [accessed 20 October 2014].

Zhang, C., and Hammad, A. 2012. Improving lifting motion planning and re-planning of cranes with consideration for safety and efficiency. Adv. Eng. Inf. 26(2):396-410. doi: 10.1016/j.aei.2012.01.003

Zhang, C., Hammad, A., and Rodriguez, S. 2012. Crane poses estimation using UWB real-time location system. J. Comput. Civ. Eng. 26(5):625-637. doi: 10.1061/ (ASCE) CP.1943-5487.0000172 
Table 1. Collection inputs for classification model

\begin{tabular}{ll}
\hline \multicolumn{1}{c}{ Obstacle classes } & \multicolumn{1}{c}{ Data collection input points } \\
\hline Horizontal wall & Any one point on the wall. \\
Vertical wall & Any two different points on the wall. \\
Inclined wall (outward/inward) & Any three different points on the wall. \\
Hanging object & Front and back boundary points, leftmost and rightmost points. \\
Ground cylinder object & Leftmost point, highmost point, and rightmost point \\
Ground cube object & Leftmost point, rightmost point, front boundary point, and back \\
& boundary point. \\
Inclined ground object & Leftmost point, rightmost point, front boundary point, back \\
& boundary point, and additional three different points on \\
& inclined wall of the object. \\
\hline
\end{tabular}

Table 2. Example of track-sector datasheet

\begin{tabular}{|c|c|c|c|c|c|c|c|}
\hline \multirow{2}{*}{$\varnothing-\left(\varnothing+0.1^{o}\right)$} & \multicolumn{7}{|c|}{$d-(d+0.1 m)$} \\
\hline & $0-0.1 \mathrm{~m}$ & $0.1-0.2 \mathrm{~m}$ & $0.2-0.3 \mathrm{~m}$ & $0.3-0.4 \mathrm{~m}$ & $\ldots \ldots$ & $99.8-99.9 \mathrm{~m}$ & $99.9 \mathrm{~m}-100 \mathrm{~m}$ \\
\hline $0^{o}-0.1^{o}$ & {$[0,100]$} & {$[0,100]$} & {$[6.8,100]$} & {$[6.8,100]$} & $\ldots \ldots$ & {$[100,100]$} & {$[100,100]$} \\
\hline $0.1^{o}-0.2^{o}$ & {$[0,100]$} & {$[0,100]$} & {$[6.8,80]$} & {$[6.8,80]$} & $\ldots \ldots$ & {$[100,100]$} & {$[100,100]$} \\
\hline $0.2^{o}-0.3^{o}$ & {$[0,80]$} & {$[0,80]$} & {$[6.8,80]$} & {$[6.8,80]$} & $\ldots \ldots$ & {$[100,100]$} & {$[100,100]$} \\
\hline$\ldots \ldots$ & $\cdots \cdots$. & $\ldots \ldots$ & $\ldots \ldots$ & $\ldots \ldots$ & $\ldots \ldots$ & $\ldots \ldots$ & $\ldots \ldots$. \\
\hline $359.9^{\circ}-360.0^{\circ}$ & {$[100,100]$} & {$[100,100]$} & {$[100,100]$} & {$[100,100]$} & & {$[100,100]$} & {$[100,100]$} \\
\hline
\end{tabular}

Note ...... = suspension points. 


\section{FIGURE CAPTIONS:}

Fig.1. Qy80v all-terrain crane produced by the Zoomlion Company in China

Fig.2. Hardware topology of lifting scheme planning system

Fig.3.Overall function chart of lifting scheme planning system

Fig.4.The cylinder coordinate system of a crane

Fig.5. Flowchart of the real-time optimization process

Fig.6. Example of calculating the boom length range for the maximal amplitude

Fig.7. Example of selecting the lifting boom length and elevation angle

Fig.8. Calculate elevation angle for a certain rotation angle

Fig.9. One onsite lifting scenario

Fig. 10. Screenshot of the user interface to collect obstacle information

Fig.11. Screenshot of the user interface to collect lifting object information

Fig.12. Screenshot of the simulation interface for the lifting planning system 


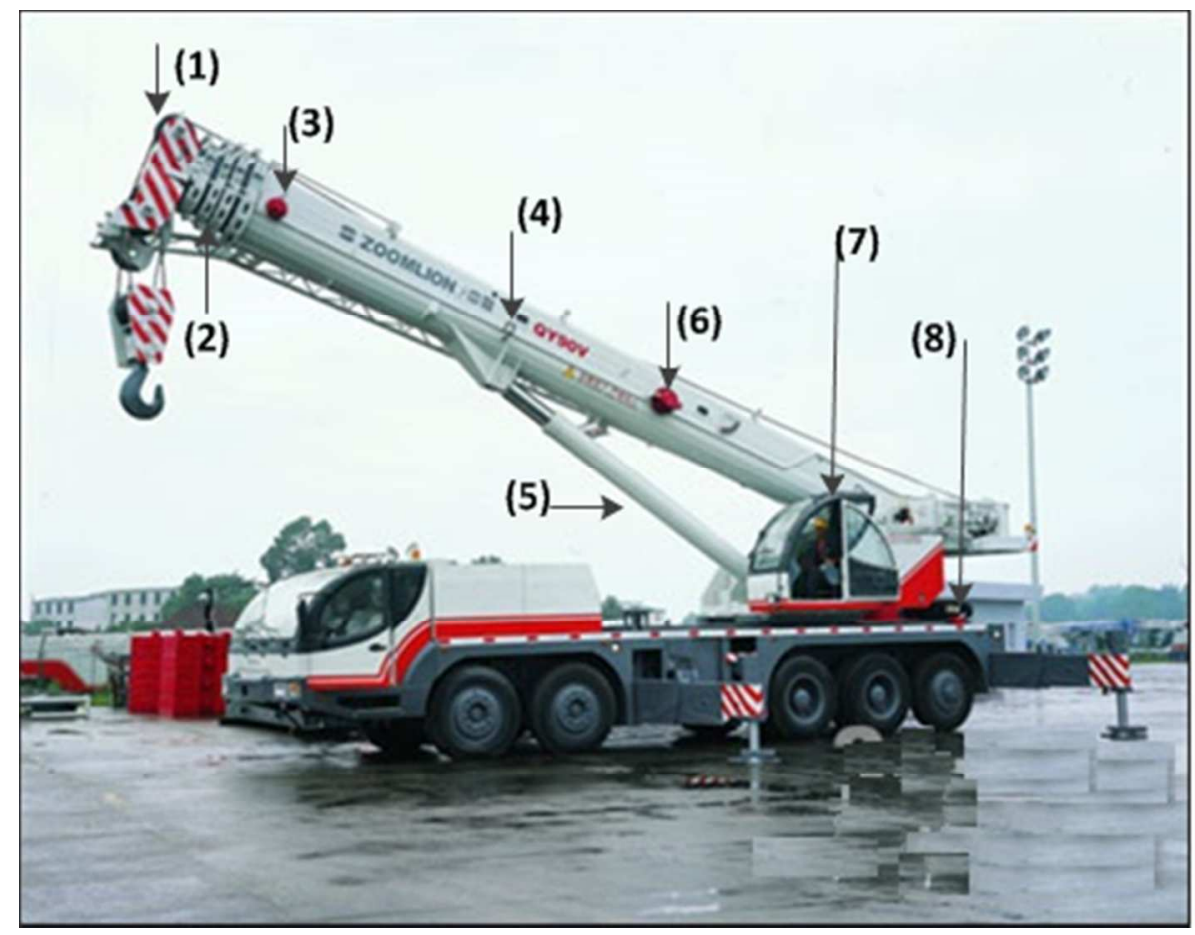

Fig.1. Qy80v all-terrain crane produced by the Zoomlion Company in China $119 \times 93 \mathrm{~mm}(96 \times 96 \mathrm{DPI})$ 


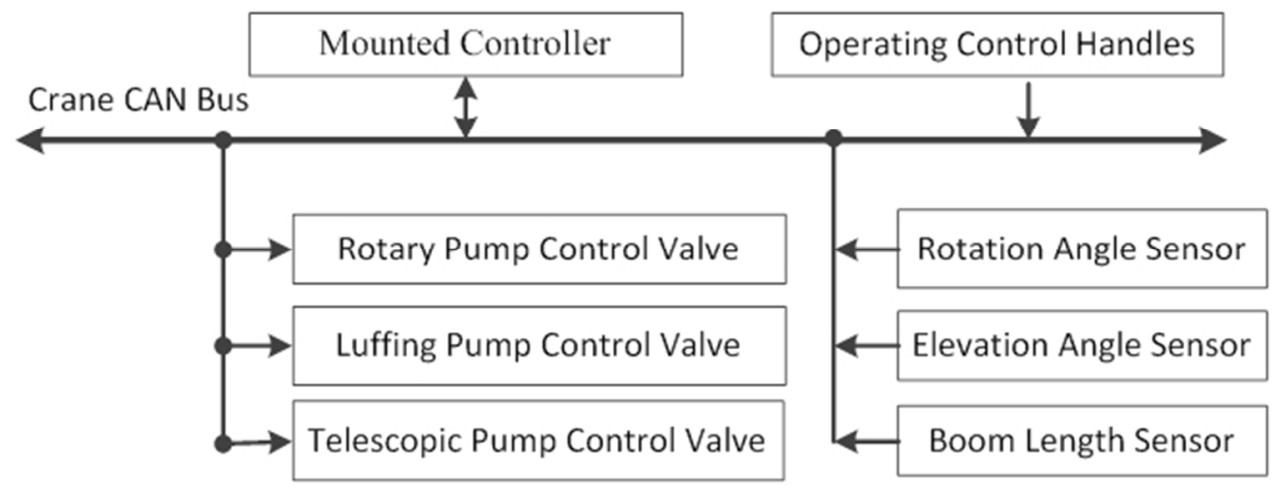

Fig.2. Hardware topology of lifting scheme planning system $178 \times 66 \mathrm{~mm}(96 \times 96 \mathrm{DPI})$ 


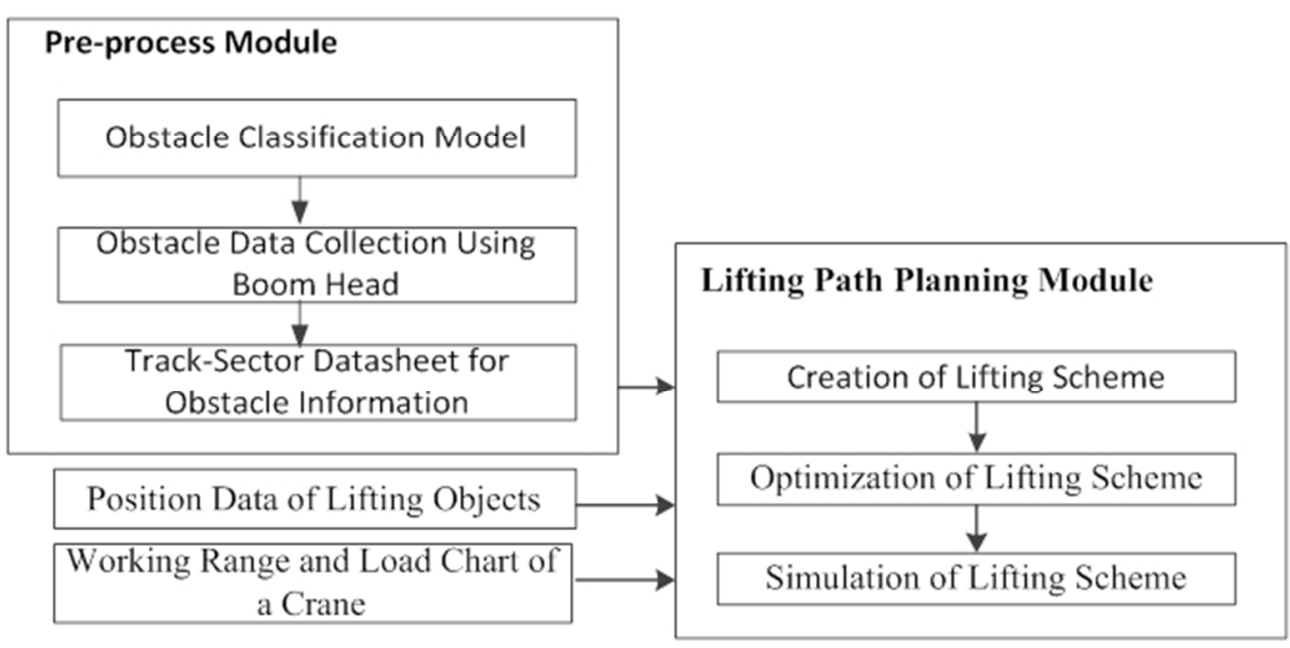

Fig.3.Overall function chart of lifting scheme planning system $179 \times 87 \mathrm{~mm}(96 \times 96 \mathrm{DPI})$ 

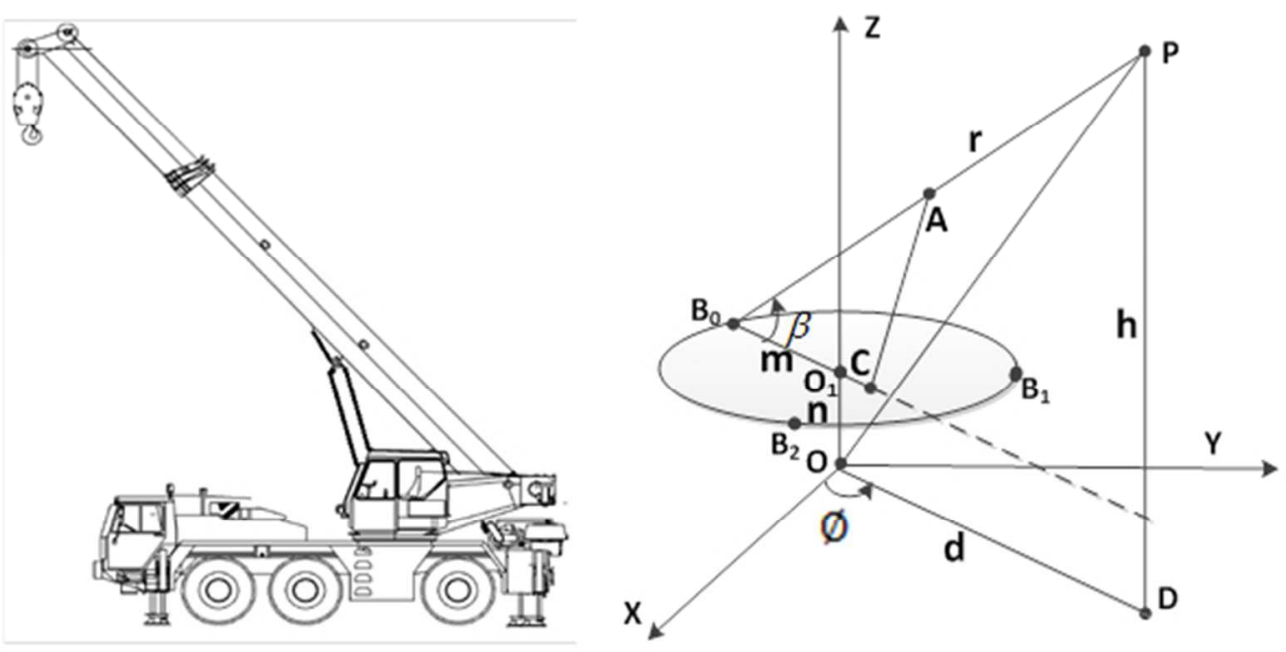

Fig.4.The cylinder coordinate system of a crane $157 \times 79 \mathrm{~mm}$ (96 x 96 DPI) 


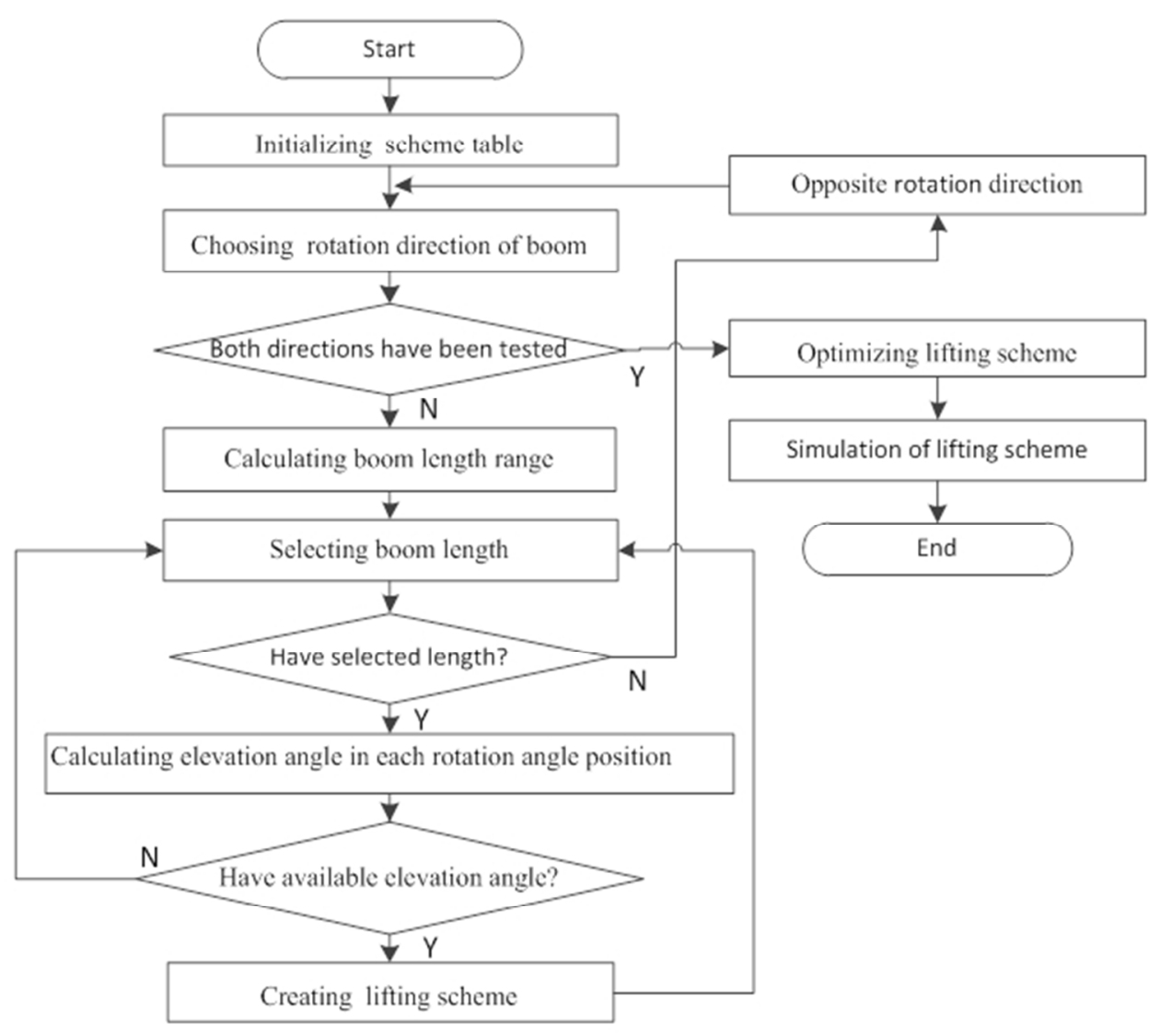

Fig.5. Flowchart of the real-time optimization process $176 \times 149 \mathrm{~mm}(96 \times 96$ DPI) 


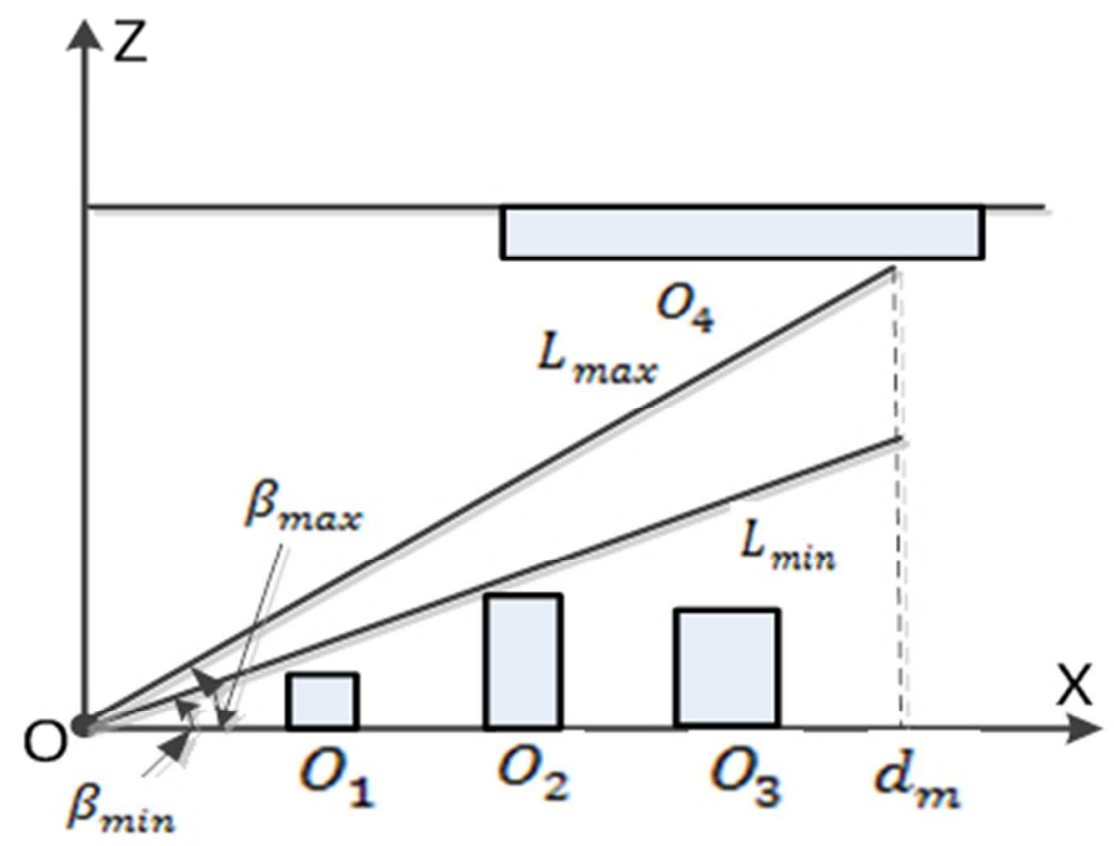

Fig.6. Example of calculating the boom length range for the maximal amplitude $117 \times 92 \mathrm{~mm}(96 \times 96 \mathrm{DPI})$ 

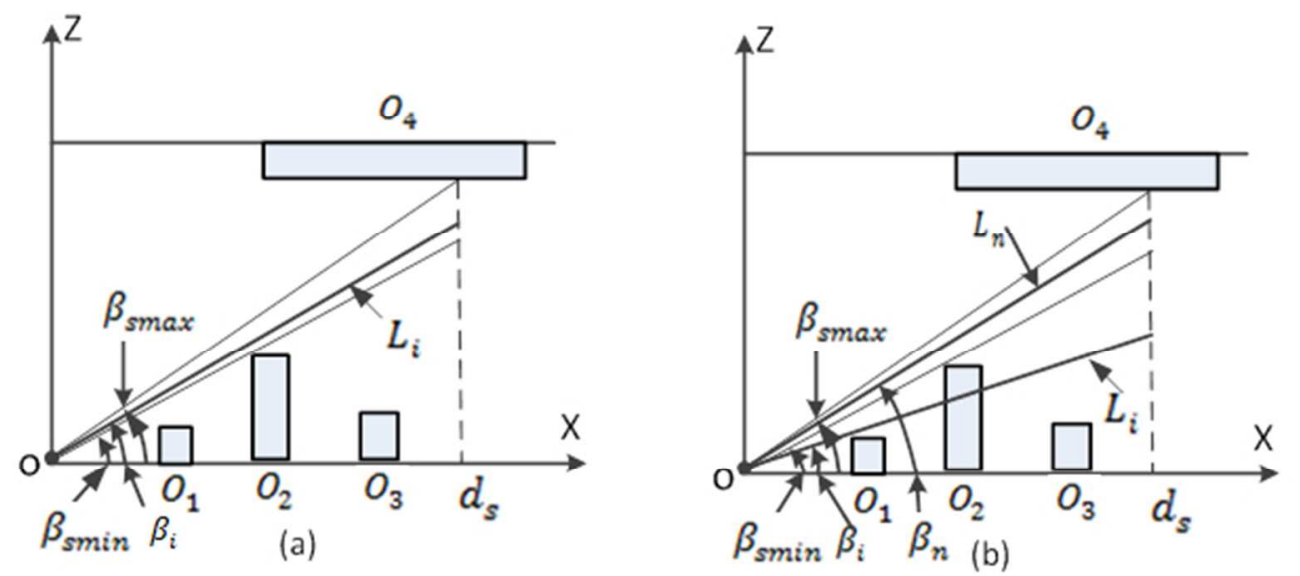

Fig.7. Example of selecting the lifting boom length and elevation angle $163 \times 74 \mathrm{~mm}(96 \times 96 \mathrm{DPI})$ 


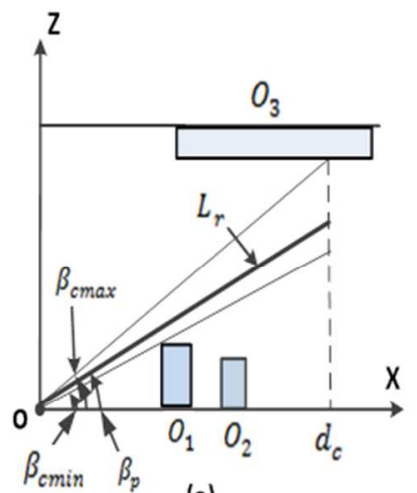

(a)

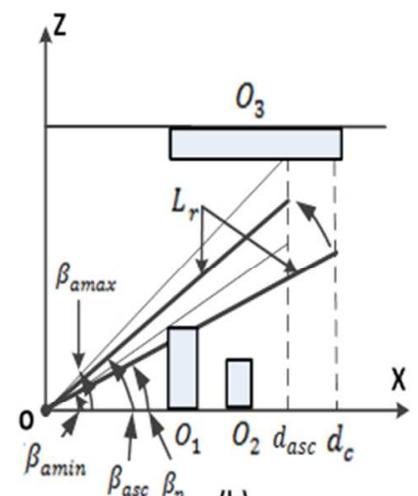

(b)

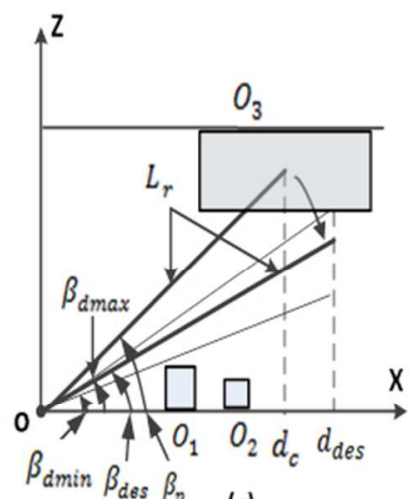

(c)

Fig.8. Calculate elevation angle for a certain rotation angle $203 \times 83 \mathrm{~mm}(96 \times 96$ DPI) 


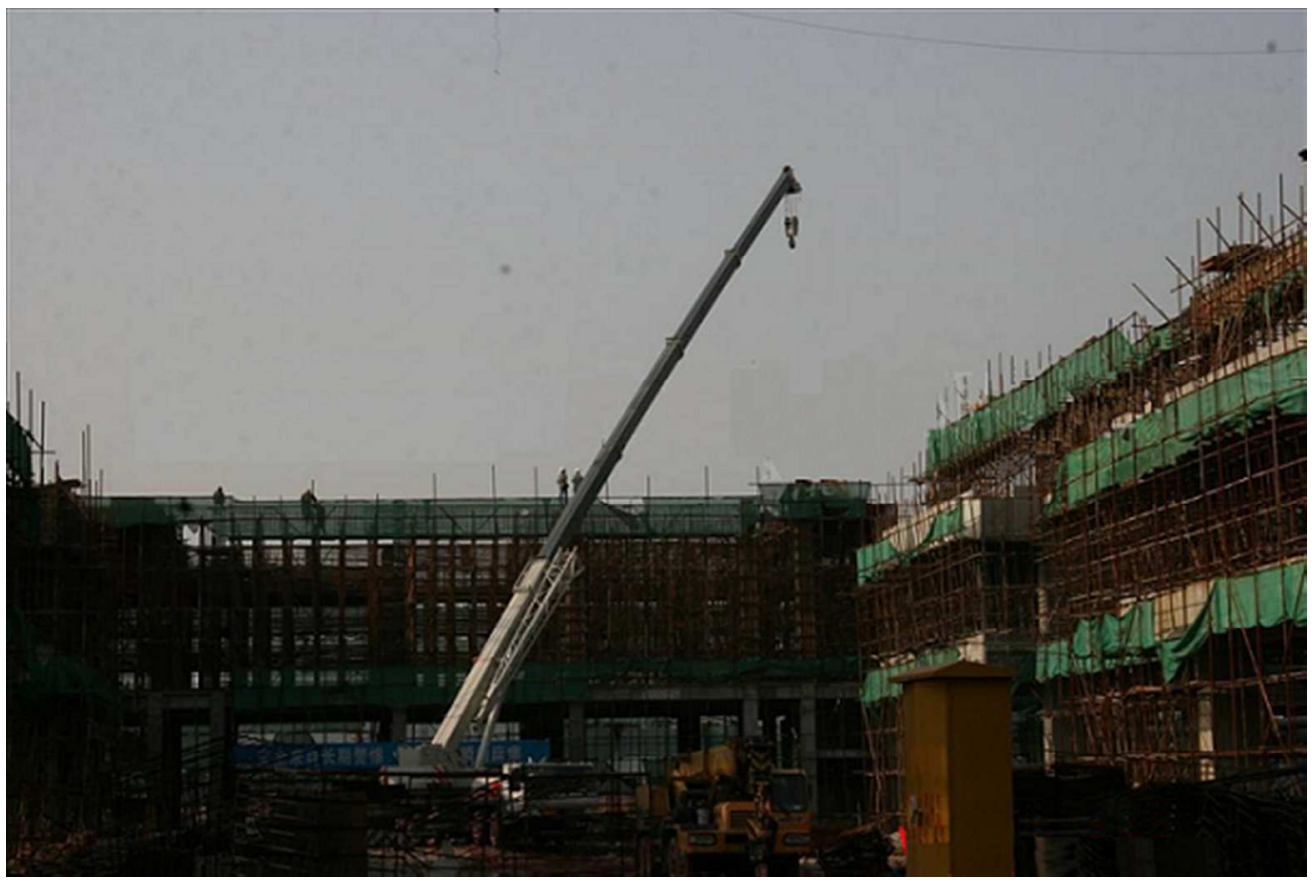

Fig.9. One onsite lifting scenario $160 \times 106 \mathrm{~mm}(96 \times 96 \mathrm{DPI})$ 
Real-Time State: RotationAngle: 79.4; ElevationAngle: 48.4; BoomLength:43.5m;

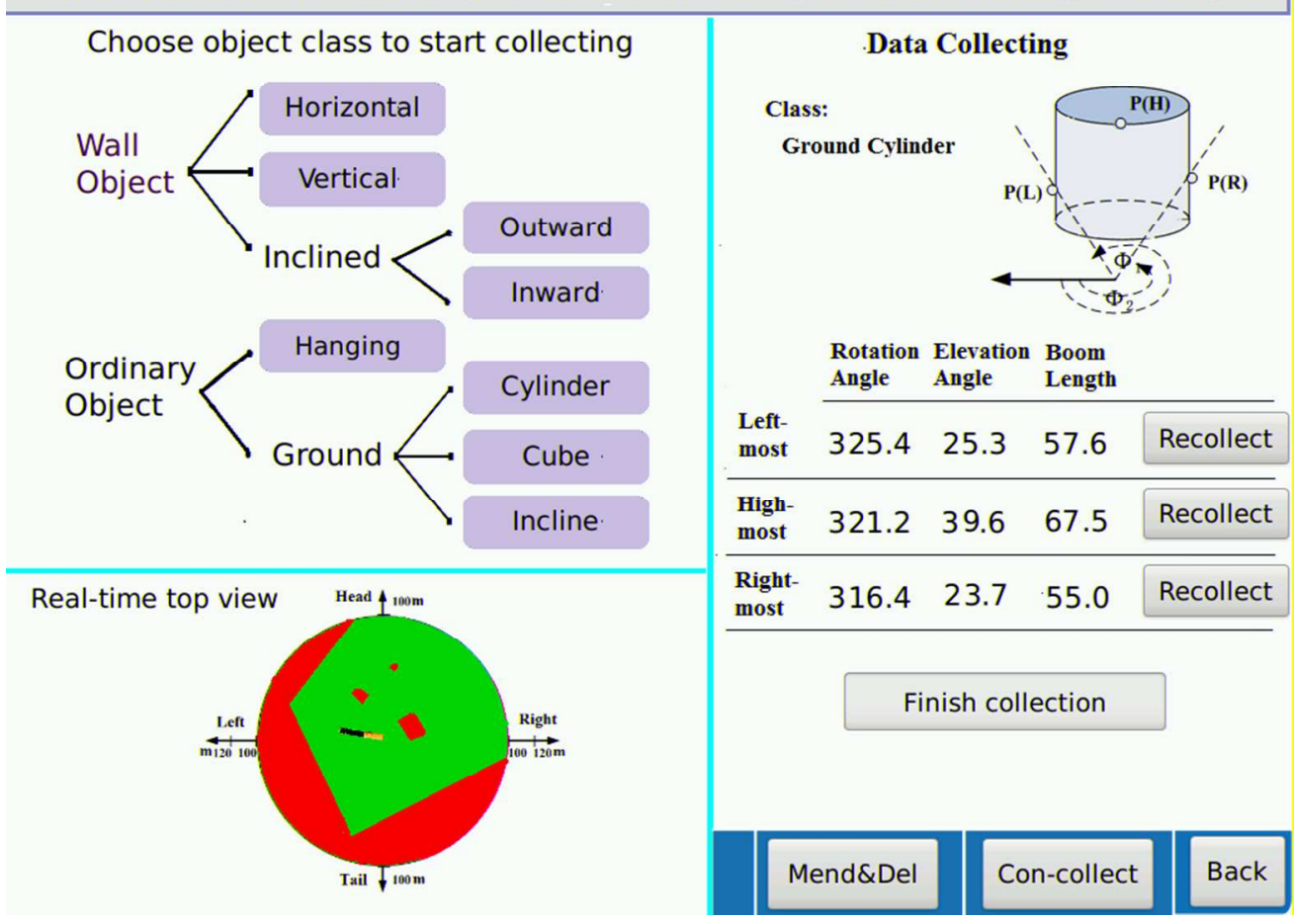

Fig.10. Screenshot of the user interface to collect obstacle information $270 \times 203 \mathrm{~mm}(96 \times 96 \mathrm{DPI})$ 


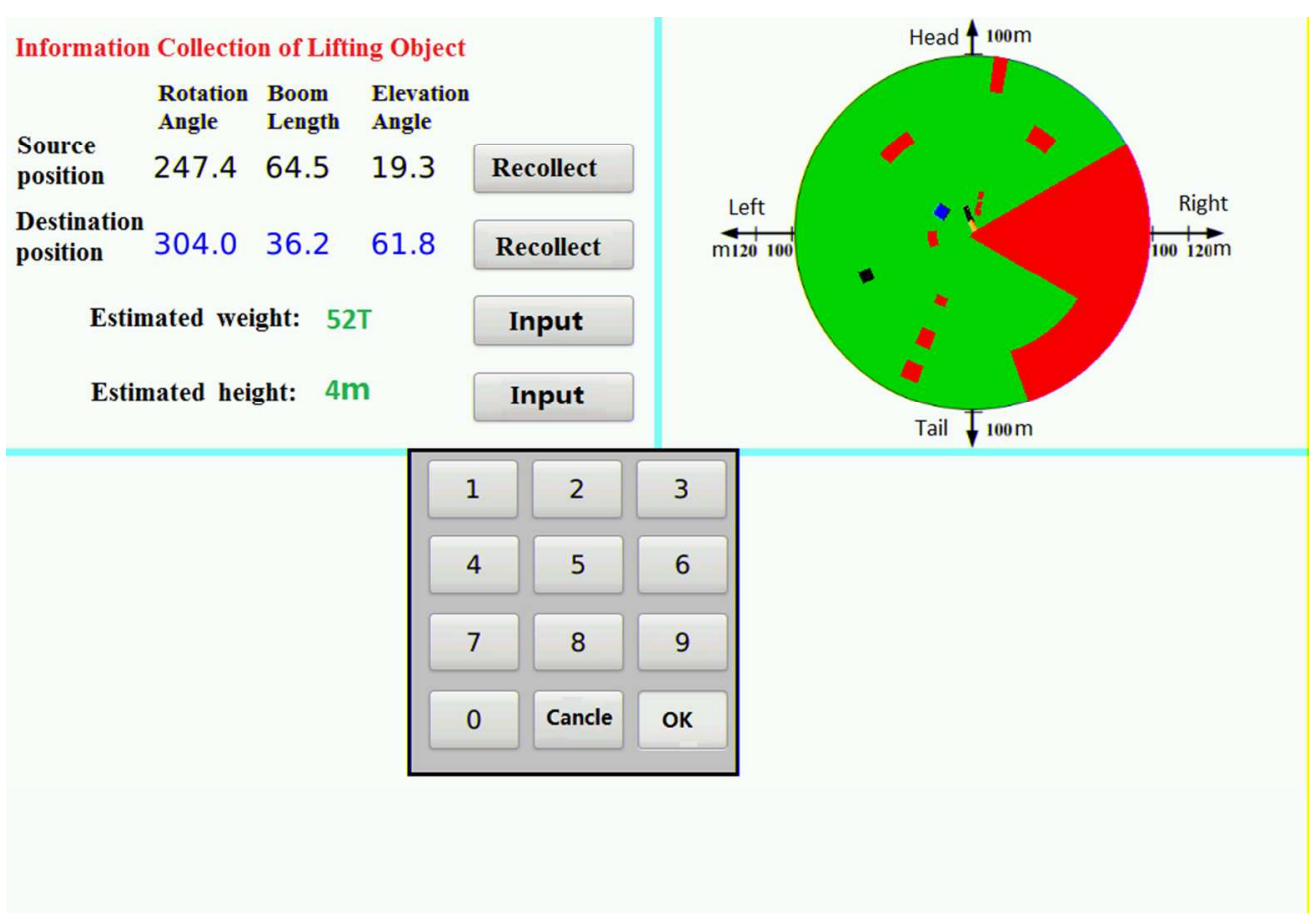

Fig.11. Screenshot of the user interface to collect lifting object information $270 \times 186 \mathrm{~mm}(96 \times 96 \mathrm{DPI})$ 


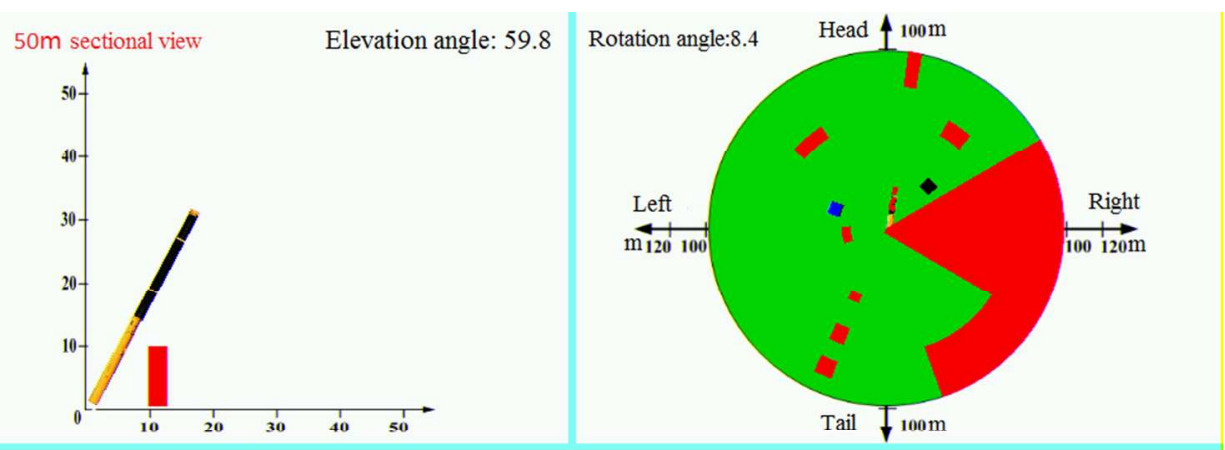

\begin{tabular}{|c|c|c|c|c|c|c|c|c|c|c|c|}
\hline \multicolumn{9}{|c|}{ Rotation direction: Clockwise ; Crane length: 23.0m; Cable combination: 1111; Multiple ratios: 10. } \\
\hline No. & Rot.Angle & Ele.Angle & No. & Rot.Angle & Ele.Angle & No. & Rot.Angle & Ele.Angle & No. & Rot.Angle & Ele.Angle \\
\hline 1 & 46.0 & 36.4 & 7 & 40.0 & 36.4 & 13 & 34.0 & 39.0 & 19 & 28.0 & 39.0 \\
\hline 2 & 45.0 & 36.4 & 8 & 39.0 & 36.4 & 14 & 33.0 & 39.0 & 20 & 27.0 & 39.0 \\
\hline 3 & 44.0 & 36.4 & 9 & 38.0 & 36.4 & 15 & 32.0 & 39.0 & 21 & 26.0 & 39.0 \\
\hline 4 & 43.0 & 36.4 & 10 & 37.0 & 39.0 & 16 & 31.0 & 39.0 & 22 & 25.0 & 39.0 \\
\hline 5 & 42.0 & 36.4 & 11 & 36.0 & 39.0 & 17 & 30.0 & 39.0 & 23 & 24.0 & 39.0 \\
\hline 6 & 41.0 & 36.4 & 12 & 35.0 & 39.0 & 18 & 29.0 & 39.0 & 24 & 23.0 & 39.0 \\
\hline Para & Sch_create & Up_page & Down_page & Simulation & Sch_recreate & Main \\
\hline
\end{tabular}

Fig.12. Screenshot of the simulation interface for the lifting planning system $270 \times 203 \mathrm{~mm}(96 \times 96 \mathrm{DPI})$ 